\title{
¿QUIÉNES SON LOS VERDADEROS FORMALISTAS \\ EN LA TEORÍA DE LA DECISIÓN JUDICIAL? ${ }^{1}$
}

\author{
JuAn Antonio García Amado² \\ UNIVERSIDAD DE LEÓN, ESPAÑA
}

\section{RESUMEN:}

Partiendo de la distinción, entre teorías formalistas de la validez jurídica y teorías formalistas de la decisión judicial, se señala que en el siglo XX, las teorías formalistas de la validez judicial, por ejemplo la de KELSEN, han sido, como todo el iuspositivismo de la época, teorías antiformalistas de la decisión judicial, mientras que el formalismo de la decisión de los jueces lo heredaban las doctrinas iusmoralistas, que afirman la única respuesta correcta para cada caso y niegan, o convierten en excepcional, la discrecionalidad judicial. El actual neoconstitucionalismo principialista y ponderador es una de esas doctrinas formalistas de la decisión judicial. En su forma canónica de hoy, viene marcado por la síntesis que hace ALEXY, entre la jurisprudencia de conceptos alemana y Dworkin, a lo que AleXY añade un método acabado de ponderación. De esa manera, este constitucionalismo principialista y ponderador es una especie de reflejo invertido de aquella metafísica decimonónica de la jurisprudencia de conceptos. Por esa vía, la metafísica alemana sigue hoy impregnando la teoría del Derecho continental y, especialmente, en América Latina.

1 Artículo recibido el 4 de noviembre de 2019 y aprobado el 27 de noviembre de 2019

2 Catedrático de Filosofía del Derecho en la Universidad de León. ORCID: 0000-0003-3096-4428 


\section{PALABRAS CLAVE:}

Formalismo, decisión judicial, ponderación, argumentación, Neoconstitucionalismo, jurisprudencia de valores

\section{ABSTRACT:}

Starting from the distinction, between formalistic theories of legal validity and formalistic theories of the judicial decision, it is pointed out that in the twentieth century, formalistic theories of judicial validity, such as that of KELSEN, have been, like all the iuspositivism of that time, anti-formal theories of the judicial decision, while the formalism of the decision of the judges was inherited by the iusmoralist doctrines, which affirm the only correct answer for each case, and deny, or make exceptional, judicial discretion. The current principlist and pondering neoconstitutionalism is one of those formalistic doctrines of the judicial decision. Today in its canonical form, it is marked by the synthesis made by AleXY, between the German jurisprudence of concepts and DwORKIN, to which AlEXY adds a finished method of weighing. In this way, this mainstream and weighting constitutionalism is a kind of inverted reflection of that nineteenth-century metaphysics of jurisprudence of concepts. In this way, German metaphysics continues to permeate the theory of continental Law and, specially, in Latin America.

\section{KEYWORDS:}

Formalism, judicial decision, weighing, argumentation, Neoconstitutionalism, jurisprudence of values 


\section{Planteamiento de la cuestión y breves notas sobre algunos mitos y lugares comunes del constitucionalismo de nuestros días}

En la actual teoría y filosofía del Derecho y creo que de manera muy destacada en América Latina, están muy extendidos una serie de lugares comunes, que podríamos sintetizar del siguiente modo, atendiendo nada más que a la temática, que en este trabajo nos interesa:

a) El positivismo jurídico es formalista, mientras que las corrientes antipositivistas o pospositivistas son antiformalistas;

b) El constitucionalismo positivista es poco sensible a los elementos morales y políticos, que dotan de fundamento moral al Estado de Derecho, mientras que el constitucionalismo antipositivista, muchas veces llamado neoconstitucionalismo, es mucho más receptivo frente a esas bases morales de las constituciones y las defiende mucho mejor; y,

c) El iuspositivismo, en general, y, en particular, el constitucionalismo iuspositivista calza bien con planteamientos políticos y sociales de carácter conservador, mientras que el pospositivismo y el neoconstitucionalismo cuadran de mejor manera con designios progresistas y reformistas.

Tales lugares comunes conforman auténticos mitos de la teoría jurídica y el constitucionalismo de nuestros días y muy particularmente en América Latina, repito. Son muchos los que 
los cultivan de buena fe y sin conciencia de que en la base de cada uno, late una falsedad promovida, la mayoría de las veces, por teóricos de moral turbia y trayectoria dudosa al servicio de poderes políticos o económicos escasamente democráticos y, desde luego, poco propensos a la promoción sincera de los derechos fundamentales $\mathrm{y}$, menos, de los derechos sociales.

No es propósito de este escrito el desmontar en detalle cada uno de esos mitos, que se conjugan al modo de una ideología como falsa conciencia de juristas ingenuos, y hasta da un poco de vergüenza ajena reparar en quienes en verdad se creen tales patrañas ${ }^{3}$, sin respaldo histórico, ni textual. Nada más voy a resaltar lo que podríamos llamar la paradoja del formalismo, consistente en que en la teoría de la decisión judicial, los verdaderos y más propiamente formalistas, son los que se dicen antipositivistas, principialistas y ponderadores. En este punto, hay que empezar por deshacer la confusión entre teorías formalistas de la validez de las normas jurídicas y teorías formalistas de la decisión judicial.

Son teorías formalistas de la validez las que mantienen, dentro de un sistema jurídico, el que sea, que una norma jurídica es válida, si satisface ciertas condiciones, que son formales, en sentido amplio de la expresión: si dicha norma ha sido creada por el

3 Abochorna pensar que todavía pueda haber quien se diga profesor de Derecho y siga repitiendo que el iuspositivismo kelseniano fue culpable de las inequidades jurídicas del nazismo, o no caiga en la cuenta de que así como ha habido en el siglo XX iusmoralistas indudablemente demócratas, no escasean por ese lado los que han bendecido dictaduras, haciéndolas pasar por encarnación del Derecho natural o recreación de la verdadera justicia, mientras que están fuera de toda duda los servicios a la teoría y la práctica democrática, que han prestado autores iuspositivistas como KELSEN, Ross, Hart, BobBio, Ferrajoli, etc. 
órgano y con el procedimiento, que se estipula en otras normas del mismo sistema jurídico. La de KELSEN es, posiblemente, el ejemplo más radical de las teorías formales o formalistas de la validez jurídica.

Son teorías formalistas de la decisión judicial ${ }^{4}$ las que afirman que el juez puede y debe decidir correctamente los casos que se le someten, mediante la aplicación de un método de razonamiento, o un procedimiento intelectual que le permita hallar en el sistema jurídico la solución única, correcta (o casi), que en éste se contiene para cada pleito, sin que en tal proceso de decisión del juez, tenga que darse -o casi sin que tenga que darse- ningún elemento de valoración subjetiva, ninguna parte de discrecionalidad judicial. En este ámbito de la decisión judicial, todos los autores que a lo largo del siglo xx y hasta hoy, se pueden denominar como iuspositivistas y sean cuales sean las variantes de su iuspositivismo, son profundamente antiformalistas, pues todos, en mayor o menor medida, niegan que la decisión judicial correcta pueda objetivamente hallarse para cada caso o casi, a base de aplicar métodos lógicos, mecánicos, aritméticos o puramente formales, y todos resaltan el insoslayable componente de discrecionalidad judicial. LLega hasta tal punto esto, que una de las notas definitorias del iuspositivismo jurídico del siglo XX es precisamente esa: la afirmación de la discrecionalidad judicial. Ese antiformalismo iuspositivista puede ser muy radical, como en el caso del iuspositivismo empirista del realismo jurídico escandinavo; puede ser muy fuerte, aunque matizado por la asunción del componente ideológico, que acompaña la autopercepción del juez como vinculado a la ley (KELSEN), o

4 Sobre las teorías formalistas de la decisión judicial, véase más ampliamente en GARCíA AMADO, J. A. 2012. 
puede ir de la mano de una filosofía política, que haga énfasis en el sustrato moral de los sistemas jurídicos modernos y que propugne que los jueces hagan un uso de su discrecionalidad lo más leal posible con tal sustrato moral (FERRAJOLI).

En ese tema de la decisión judicial, el formalismo ha tenido dos configuraciones principales: el paleopositivismo o positivismo metafísico del siglo XIX, encarnado, en el Derecho continental, por la escuela de la exégesis y la jurisprudencia de conceptos, y el iusmoralismo principialista y ponderador, el cual tiene su antecedente primero en la jurisprudencia de valores, toma la noción de principios jurídicos de DwORKIN y halla su síntesis metodológica en la doctrina de Alexy y su diseño de la ponderación, como método para alcanzar las decisiones correctas de cada caso, en el marco de una ética de signo constructivista y con muy escaso espacio para la discrecionalidad judicial. Esa es la paradoja histórica que pretendo acreditar aquí: el principialismo alexyano y el conceptualismo decimonónico, el del primer JHERING, estructuralmente se parecen como dos gotas de agua, pues comparten la fe en la perfección del sistema jurídico, rellenan de metafísica el Derecho y piensan que hay un método que permite al juez arribar con objetividad y mucha certeza a la solución única correcta para cada caso.

\section{Racionalidad del Derecho vs. racionalidad del juez}

En la teoría del Derecho, se han dedicado ingentes esfuerzos y ríos de tinta para fundamentar la decisión racional de casos jurídicos. Siempre se conjugan dos elementos para este propósito: la racionalidad que se predique del Derecho mismo, en tanto materia, objeto, o realidad y el grado de esfuerzo, 
metodológicamente guiado, que se le pida al sujeto, que en Derecho decide, a fin de alcanzar la decisión jurídica correcta. Y rige prácticamente sin excepción la siguiente regla: [...] cuanto más alta es la racionalidad que al derecho como tal (y sea cual sea la materia prima de lo jurídico, según la teoría de turno) se le atribuye, menor es el énfasis que se pone en el esfuerzo reflexivo o cognitivo del juez; y, a la inversa, [...] cuanto mayor es el énfasis en los defectos estructurales e inevitables del Derecho, en tanto que medio regulador, más se destaca el papel determinante del conocimiento, la agudeza metodológica o las actitudes del juez o sujeto llamado a decidir los casos jurídicos.

Generalmente y, en particular, en la literatura anglosajona, se presenta el panorama como de muy simple contraposición, entre enfoques formalistas y enfoques propios del llamado realismo jurídico (norteamericano). Formalistas serían aquellas viejas teorías que pensaban, que la decisión judicial consiste en un muy elemental silogismo, en el cual se ponen en relación los hechos y la norma, que a ellos se ajusta y surge, sin esfuerzo del juez, el fallo, con poco que argumentar, pues allí donde las dos realidades se ajustan perfectamente, la realidad fáctica y la normativa, poco más cabe añadir, si no es mostrar el prodigio lógico y hasta metafísico. A ese formalismo habría venido a ponerlo en serios apuros el realismo de aquellos jueces y profesores, que desde las primeras décadas del siglo $\mathrm{XX}$, nos hicieron conscientes de que no es la lógica, sino la ideología la que mueve las decisiones judiciales, y que no es la competencia deductiva, sino la muy personal y situada intuición, la que determina los contenidos de los fallos.

Pero sin que quepa invalidar por completo el anterior esquema, habría que matizar que, al menos en los ámbitos del llamado 
Derecho continental, las cosas son algo más complejas. No podemos comprender la mutación, en el modelo de racionalidad jurídica, si atendemos solo al elemento subjetivo al modo como el juez razona, o a la base subjetiva de su decisión. Hay que considerar también la idea del Derecho y, al menos en el Derecho continental, lo determinante fue el cambio en la idea de lo jurídico.

El tránsito del siglo XIX al Xx fue, en la teoría jurídica, el paso del modelo del Derecho perfectamente racional -o casi- al modelo del Derecho no perfecto, defectuoso, por así decir. Sobre la escuela francesa de la exégesis influía el llamado mito del Legislador racional $^{5} \mathrm{y}$, en consecuencia, el Derecho positivado en el código era contemplado como Derecho perfectamente racional. El sistema jurídico tenía tres propiedades, que lo hacían poco menos que perfecto: plenitud, coherencia y claridad; es decir, no había lagunas, ni antinomias y los problemas interpretativos o no existían, o eran desdeñables, o se podían resolver con ayuda de un método bastante sencillo generalmente consistente en la averiguación, mediante indicios históricos patentes, de cuál había sido la voluntad del Legislador. Si, además, se pensaba que los hechos hablaban por sí mismos y que poca o nula relevancia tenía la valoración de la prueba por el juez ${ }^{6}$, mero fedatario de lo fácticamente acaecido, era fácil desembocar en la visión de la decisión judicial como simple silogismo o elemental subsunción,

5 Sobre los orígenes y alcances de ese mito, véase especialmente Calvo García. 1986, p. 103 y ss.

6 Perfecto Andrés IbÁÑez habla de decisionismo intimista para referirse a aquel viejo hábito, no tan lejano, de pasar de puntillas sobre la motivación de los hechos y su prueba en la sentencia. IBÁÑEZ ANDRÉs, P. 2007, p. 9. 
sin componentes creativos o subjetivos, pura objetividad como parangón de lo científico, así como el modo en que la razón teórica y la razón práctica, se daban la mano en el campo de la praxis jurídica.

Para los alemanes de la jurisprudencia de conceptos, también en el XIX los esquemas de fondo no eran muy diferentes pese a que, para ellos, no contaba de igual manera la idea del Legislador racional y ya que en los territorios alemanes, la codificación no se había impuesto, desde los inicios del siglo, como en Francia, sino que fue cristalizándose con más lentitud y en medio de muy conocidos debates ${ }^{7}$. Lo que cambiaba era la materia prima de lo jurídico, pues donde los franceses veían en los preceptos del código la esencia racional y plenamente objetiva del Derecho, los alemanes ubicaban tal racionalidad y objetividad perfectas en las ideas o conceptos, que componían algo así como la pirámide ontológica del Derecho. Baste recordar cómo, en Derecho privado, la idea matriz es la autonomía de la voluntad y de ella, se van deduciendo, con una especie de necesidad derivada de algo así como la lógica material, los contenidos que dan su ser y su sentido a los conceptos, que hacia abajo se encadenan, según su nivel de abstracción: negocio jurídico, contrato, compraventa y demás contratos, etc. Si los franceses se subsumían bajo enunciados claros, precisos y coherentes del Code, los alemanes encajaban, bajo los contenidos necesarios e inmutables, metafísicamente impuestos e invariables de cada concepto jurídico. Al igual que los artículos del código se van desplegando, con arreglo a la figura de un árbol del saber jurídico, los conceptos jurídicos, para la ciencia jurídica alemana, se van esquematizando, conforme a los trazos de un árbol lógico y en una escala, que baja de la abstracción

$7 \quad$ No se olvide que el BGB entra en vigor el 1 de enero de 1900. 
a la concreción, paso a paso, hasta llegar a los conceptos más concretos, siempre genealógicamente dependientes de los más abstractos, que ocupan los peldaños superiores de la pirámide ${ }^{8}$.

De una manera, o de la otra, o bien porque el código encarna la autorregulación de la nación y es expresión de la sabiduría ínsita en el Legislador, que a la nación representa y a sí misma se regula, o bien porque los contenidos conceptuales o ideales de lo jurídico expresan un orden necesario del ser, un orden metafísico incontestable, lo jurídico es perfecto y plenamente racional y sus reglas -se deriven de las palabras del código o de los contenidos de cada concepto- permiten pensar que hay, para cada caso, una única solución correcta, predeterminada en el sistema jurídico y que el juez puede y debe hallarla, en cada litigio que resuelva. Bajo tales puntos de vista, los jueces no crean Derecho, no ejercen discrecionalidad y cuentan con un método plenamente operativo para extraer, con acierto, la solución, que para cada asunto yace en el subsuelo del sistema, sea ese subsuelo semántico y lógico, o sea ontológico, o metafísico. Tal vez los seres humanos resultan sumamente imperfectos y no muy sabios y lo mismo los jueces como humanos que son, pero poco importa, si la perfección está en el Derecho mismo y ese humano, quien juzga, no tiene que hacer mayor cosa que, con ayuda de elementales consignas metodológicas, sacar del sistema jurídico la solución única, correcta, para cada caso, por completo predeterminada a su voluntad, independiente de su subjetividad, no condicionada en modo alguno por sus preferencias personales, o sus convicciones

8 Pero no según las pautas, de lo que llamaría KeLSEN, un sistema dinámico, sino de una especie de sistema estático, en el cual cada concepto inferior deriva sus contenidos de un concepto superior, en cuanto concreción o adecuación de éste para un ámbito más preciso. 
morales, o ideológicas. Al igual que las verdades científicas no dependen de lo que al físico o al químico le guste o le convenga, la verdad de las soluciones jurídicas, lo que sea para cada caso, la solución jurídica verdadera no depende de nada que esté a merced de la conciencia, o la opinión del juez, sino de un orden objetivo, que el juez ni manipula, ni condiciona, pero que puede conocer, si emplea el método debido.

Fue esa concepción optimista y metafísica, idealista y confiada del Derecho la que sucumbió por completo con el paso del siglo XIX al XX. En Francia, la crítica destructiva de GÉNY ${ }^{9}$ no dejó de la escuela de la exégesis títere con cabeza, justo en el cambio de siglo, y luego llegó el particular sociologismo jurídico de los franceses y remató la faena. En Alemania, el JHERING, de la segunda época, inicia los ataques cuando faltan más de tres décadas para que el XIX termine y con el cambio de siglo. se consuma el descrédito definitivo de la jurisprudencia de conceptos, que muere bajo el fuego cruzado de KELSEN y su normativismo antimetafísico y el relativismo moral de EHRLICH y los que, bajo su ejemplo, se adscriben al sociologismo jurídico de la escuela de Derecho libre (Fuchs, KanTOROwICZ, IsAY, etc.) de la jurisprudencia de interese ${ }^{10}$, que funda HECK y desarrollan autores, tales como MüLLER-ERZBACH o RüMELIN, etc.

9 Sobre GÉNY y su crítica a la escuela de la exégesis, es fundamental ver la obra de BERNUZ BENíTEZ, M. J. 2006; sobre el contexto en que surge esa crítica de GÉNY, Ibíd. p. 17 y ss; y, sobre las características de la escuela de la exégesis, Ibíd. p. 72 y ss.

Véase García Salgado, M. J. 2011. 
Se puede decir, con bastante seguridad, que en los años veinte $\mathrm{y}$ treinta del siglo $\mathrm{xx}$, no queda en Europa un solo autor informado e influyente ${ }^{11}$, que siga anclado en la visión optimista e hiperracionalista, que de lo jurídico se tenía en el XIX y que todavía sostenga, que el Derecho es obra acabada de la razón, que la decisión judicial es un elemental silogismo, o una subsunción muy sencilla, que los valores del juez no influyen determinantemente en sus fallos, que no hay discreción judicial, o que no importan las razones de la sentencia, porque si ha sido correcto el razonamiento del juez, en el fallo se plasma la razón del Derecho. Y el realismo jurídico escandinavo firma la sentencia definitiva de muerte del optimismo de los juristas.

En medio de las enormes polémicas que en la primera mitad del siglo y en la teoría jurídica europea enfrentan a normativistas con empiristas, a psicologistas con sociologistas, a neokantianos y a neohegelianos, etc., etc., hay un acuerdo de fondo, en el cual el optimismo metafísico del siglo XIX está muerto, por mucho que los legisladores se esfuercen, el Derecho es incapaz de

11 Cosa diferente es lo que siguió - ¿y sigue?- sucediendo en algunas facultades de Derecho, en las cuales la gran mayoría de los profesores ni suelen ser influyentes, ni destacan por estar muy informados, y donde la idiosincrasia jurídica decimonónica perduró, mediante una organización de la enseñanza, a medida de la vieja concepción de lo jurídico como síntesis de la razón, u objeto de un aprendizaje acrítico, memorístico y cuasireligioso, con la bien conocida aproximación de la dogmática jurídica a la dogmática teológica y un inevitable descrédito de toda pretensión de cientificidad, racionalidad, o mera utilidad de unas disciplinas jurídicas, cultivadas con celo de sacristán más que con maneras de científico social. De hecho, la mayor parte de los profesores de Derecho, aun hoy, nada saben de ciencias o disciplinas, que no sean esa tan pedestre que enseñan. 
abarcar la compleja realidad social, en que los términos jurídicos tienen siempre su halo de indeterminación y en que los jueces crean o recrean el Derecho y obran con muy amplios márgenes de discrecionalidad. Pero cuando los jueces de la República de Weimar, primero, y del nazismo, después, usaron todo ese poder, que ahora la teoría les reconocía para derribar las estructuras del Estado de Derecho, para darle marcha jurídica al crimen y para convertir en agua de borrajas los derechos subjetivos, que las leyes y los códigos reconocían por igual a los ciudadanos, la teoría jurídica sintió la necesidad de retornar a los tranquilizadores esquemas de la fe en la razón, una fe bien contrafáctica; y el idealismo empezó a decir de nuevo que donde no exista justicia, no puede haber propiamente Derecho y que allí, donde en verdad el Derecho existe, proporciona a los jueces certezas racionales, con las cuales resolver cada pleito del modo objetivamente correcto, sin discrecionalidad y sin espacio para el abuso, o la tergiversación. Esa va a ser la historia principal del pensamiento jurídico de la segunda mitad del siglo pasado y hasta la actualidad o poco menos.

\section{La jurisprudencia de valores alemana y su conservadurismo}

Ante lo que podríamos llamar la duda sobre el elemento humano en lo jurídico, se imponía re-racionalizar el Derecho y para lograr eso, había que alejar la teoría jurídica del positivismo, que es la doctrina que afirma que las normas son jurídicas, en razón de las propiedades independientes de su condición moral, de la legitimidad del sistema político en el que rijan y de la racionalidad mayor o menor de su uso. El primer y decisivo paso lo da, en Alemania, la jurisprudencia de valores, que tiene su expresión emblemática en una afirmación, que en 1958 aparece, tanto en 
el comentario que GüNTER DÜRIG ${ }^{12}$ publica sobre el apartado 1, del parágrafo 1 de la Ley Fundamental de Bonn ${ }^{13}$, como en la sentencia del Tribunal Constitucional alemán, en el caso Lüth y que reza así: la Constitución es un orden objetivo de valores.

La naturaleza de la Constitución es concebida como esencialmente axiológica y los valores constitucionales son los primeros y más altos del orden moral en que, en su esencia, el Derecho consiste ${ }^{14}$. Y de esos supremos valores, que conforman el sustrato básico de lo jurídico, el primero es el valor dignidad, recogido en aquel apartado primero del primer parágrafo de la Constitución. Hasta tal punto es todo el orden constitucional un conjunto de valores, deducidos de ese valor primero o fundamental, y hasta tal punto los contenidos del sistema jurídico, son la plasmación normativa o regulativa de esos valores, que afirma DüRIG que aún cuando la Ley Fundamental no tuviera más texto expreso que ese primer apartado, referido a la dignidad, el contenido real de la Constitución sería el mismo, pues todo lo que tras el parágrafo 1 está escrito en la

12 Dice Uwe Wesel que DürIG es el inventor (Erfinder) del «sistema de valores» (Wertsystem) de los derechos fundamentales, noción de la que en adelante se sirvió el Tribunal Constitucional, a partir del caso Lüth. Véase WeseL, U. 2004, p. 131.

13 Recordemos que ese precepto dice que: La dignidad humana es intocable (unantatsbar).

14 Afirma Bernhard SCHLINK que: El tribunal constitucional federal se preocupó por no ser demasiado explícito en este aspecto, pero su manera de entender los derechos básicos como valores que componen un sistema de valores y de entender la acción libre como más o menos cargada de valor se fundamentó, de todas formas, en el renacimiento del Derecho natural, propio de aquella época. Esta concepción sobrevive en la manera actual de entender los derechos básicos como principios, y sobre esto último cita Schlink a Alexy. SchlinK, B. 2005, p. 47. 
Ley Fundamental, es pura deducción o desarrollo ineludible a partir del valor dignidad.

Es obvio que en la jurisprudencia de valores, al igual que en cualquier otra doctrina de impronta fuertemente iusmoralista, que, si el elemento primero del sistema jurídico auténtico es axiológico, esos valores no pueden ser de cualquier contenido, sino que han de ser los de la moral verdadera. De esa manera, cuando el juez decide, conforme a Derecho, ya no importan tanto las deficiencias o insuficiencias de los preceptos positivos, de los enunciados constitucionales, legales o reglamentarios, ya que puede completarlos, precisarlos y hacerlos plenamente coherentes, a base de verlos sobre el trasfondo de ese orden axiológico de contenidos verdaderos y necesarios. Por esta vía, y a partir de la jurisprudencia de valores, reaparece, pues, el sueño decimonónico de que el Derecho es, en su trasfondo y más allá de la superficie, un orden perfecto -completo, coherente y claro-, que encierra para cada caso una solución correcta, y de que la discrecionalidad judicial es inexistente o escasa, pues lo que al juez se le pide no es que colme lagunas, resuelva antinomias o elija interpretaciones posibles de los enunciados jurídicos, sino que realice las operaciones intelectuales, o siga las pautas metodológicas debidas, para dar con la solución objetivamente correcta para cada caso, que será la solución moralmente correcta y, simultáneamente, la solución jurídicamente adecuada, ya que Moral y Derecho se dan la mano y se aúnan en ese fondo axiológico o valorativo de lo jurídico. O, como más adelante dirá AlEXY, el Derecho es un caso especial de la razón práctica general.

La jurisprudencia de valores fue el recurso doctrinal de un constitucionalismo alemán de posguerra extraordinariamente 
conservador y que quería poner, desde la Constitución misma, cortapisas a una eventual victoria algún día de partidos de izquierdas o menos conservadores ${ }^{15}$. Eso explica algunas tremendas sentencias del Bundesverfassungsgericht, en este tiempo, en el cual supuestamente se inspiraba en los mejores contenidos de los supremos valores constitucionales.

El antiparlamentarismo de fondo y la fobia al liberalismo se disfrazaban como apelación a la densidad moral de la Constitución, la Ley Fundamental de Bonn, de la que se quería alejar toda visión o interpretación de sus términos en clave positivista, y mostrar que no importaba tanto lo que la Constitución dijera como la unidad del pueblo, bajo los valores constitucionales, que esa doctrina ultraconservadora quería amarrar para siempre, con el fin de, ante todo, hacer al sistema inmune a los cambios que pudiera pretender la izquierda, si un día ganaba las elecciones democráticas. Toda jurisprudencia de valores ha sido siempre

15 Hay algunos paralelismos o coincidencias sorprendentes y muy aleccionadoras. Cuentan RÜCKERT y SEINECKE que la jurisprudencia de conceptos, que se conoce por ese nombre, desde que así la llamó, en tono burlón, JHERING, en 1884, tuvo su apogeo en los años 40 y 50 del siglo XIX y es hija del "constitucionalismo monárquico», ya que, más allá del texto legal y contra los monarcas, se intentaba asegurar el Derecho, mediante los conceptos. Por debajo de los conceptos, a los cuales las soluciones judiciales se remitían, estaban los valores políticos, sociales, económicos y morales, que los impregnaban. RÜCKERT, y SEINECKE. 2017, p. 148 y ss.

SEINECKE explica el contexto en que aparece la que se llamó jurisprudencia de conceptos, cómo su elaboración más acabada se debe al JHERING de la primera época, el de Geist des römischen Rechts, y cuán poco importaba a esos autores, en especial a ese primer JHERING, la letra de la Ley frente a la sustancia metafísica de los conceptos. RÜCKERT, y SEINECKE. 2017, p. 42. 
bien contraria a cualquier jurisprudencia democrática, y quienes materializan la Constitución para lanzarla contra la ley que no sea formal o semánticamente inconstitucional, lo hacen siempre para apoderarse de la constitución misma y hacer pasar su moral personal por moral constitucional objetiva. Esa paradoja del constitucionalismo alemán de postguerra sigue lastrando el constitucionalismo actual de medio mundo: los profesores que interpretaban y sistematizaban la Constitución eran -y siguen siendo, muchas veces- absolutistas morales, quienes abominaban del pluralismo, la libertad, la autonomía individual y la democracia ${ }^{16}$.

Se trataba, por tanto, de hacer ver que el contenido de la Ley Fundamental, es mucho más denso y preciso de lo que la Constitución dice, y que todo cuanto en las palabras del texto constitucional queda impreciso, o ni siquiera es mencionado, está, sin embargo, perfectamente definido y regulado en ese fondo moral, que también es Constitución: la parte esencial de la Constitución. Se buscaba, pues, que pudiera el Tribunal Constitucional declarar inconstitucionales normas legales, que en modo alguno contradijeran los enunciados constitucionales, o que fueran plenamente compatibles con la semántica constitucional, pero que se opusieran a instituciones, tradiciones o reglas sociales, que ese constitucionalismo ultraconservador consideraba intocables, y que quería librar de todo riesgo de reforma por medio

16 Como nos recuerda GÜNTHER, en los años cincuente y sesenta, en Alemania, la interpretación de los derechos fundamentales, como orden de valores (Wertordnung), planteaba conscientemente un contrapeso a la teoría liberal de los derechos fundamentales y más que procurar la efectividad de los derechos, quería mantener bajo control su desarrollo y su sumisión a los intereses superiores del Estado. GÜNTHER. 2013, pp. 79-80. 
de la legislación. La historia del constitucionalismo del siglo XX nos enseña que el mejor recurso para evitar los cambios sociales, por vía legal, que más duelen a los poderes dominantes en un país, consiste en materializar la Constitución, a fin de que, digan lo que digan sus artículos, sea posible convertirla en guardiana del orden material y las prácticas establecidas, que más favorezcan a tales poderes. De Weimar para acá, el gran enemigo del constitucionalismo conservador ha sido siempre el Legislador, y la mayor desconfianza la han tenido siempre las élites políticas y jurídicas, respecto de la soberanía popular y el parlamentarismo. La forma de precaverse, ante las posibles reformas impulsadas desde los partidos de la izquierda, ha sido la de volver sus programas incompatibles con el orden constitucional. Así, por ejemplo, en aquella Alemania de los años sesenta dominada, en lo jurídico, por constitucionalistas, que, en su mayor parte, no le habían hecho ascos al nazismo en su día, importaba ante todo poner a salvo el orden tradicional de la familia y el alcance máximo de los contenidos del derecho de propiedad y, por tanto, había que agregar a los artículos de la Ley Fundamental, que a la familia o a la propiedad se referían, algo más: los valores de una moral particular y partidista, que convertían en inconstitucional el ataque contra el viejo orden familiar y económico.

\section{Subsumir y ponderar: dos métodos con un designio común}

Esa pátina conservadora, que está en los orígenes doctrinales de lo que más adelante se denominaría neoconstitucionalismo, se oculta, a base de fundir un par de decenios después, la jurisprudencia de valores con la teoría del Derecho de Ronald Dworkin ${ }^{17}$, precedente de la jurisprudencia de valores alemana. ZACCHARIA, G. 
pensador de lo jurídico, quien no es conservador en sus propósitos políticos. Dworkin combatía, en otro frente -el norteamericano o anglosajón-, estaba en otra disputa y, seguramente, no tenía ni la más lejana noticia del constitucionalismo alemán, de la jurisprudencia de valores, muy sucinta información sobre la historia de la teoría jurídica y constitucional europea y del Derecho continental. Quien sí conoce bien tanto la obra dworkiniana, como el pasado del constitucionalismo alemán es RoBERT ALEXY y a él le correspondió elaborar la gran síntesis ${ }^{18}$. Desde posturas políticas o morales, también conservadoras, pero de un conservadurismo ya no autoritario, como el de sus antecesores, sino más próximo a lo que se podría llamar la doctrina social de las iglesias cristianas -católica y protestante- a partir de los años ochenta, y con un lenguaje que abandona los viejos tonos de la metafísica y adopta ropajes analíticos, AleXY insiste en la idea de que ni el Derecho constitucional de un Estado se acaba en lo que dice su Constitución o deciden sus tribunales, ni es la Ley democrática de ese Estado constitucional acorde con la Constitución, solamente, si no violenta los términos de ésta, pues también para AleXY el verdadero Derecho es el que está de acuerdo con la moral verdadera, razón por la que la moral verdadera es la auténtica Constitución o la parte superior de toda Constitución auténtica.

2016, p. 432.

18 Indicios de cómo la jurisprudencia de valores se apoya en una metaética dubitativa o quizá poco elaborada, a medio camino, según los autores y los tiempos, entre una ética material de valores, al estilo de M. ScHELER y planteamientos consensualistas, emparentados con lo que actualmente se llama constructivismo ético, pueden verse en BYDLINSKI, F. 1992, p. 128 y ss. Véase un análisis más detallado de H. M. PAWLOWSKi, quien dentro de la jurisprudencia de valores alemana diferencia las siguientes corrientes: formal, material, normativa, objetiva y social. PAWLOWSKI, H. M. 1981, pp. 60-82. 
Puesto que ALEXY presenta su teoría fortísimamente iusmoralista, ya no en alianza con un iusnaturalismo, con aromas de incienso y bien alejado de actitudes políticas ultramontanas, dado que toma esquemas conceptuales de Dworkin, cuya filosofía política pasa por progresista, y en cuanto que actualiza la metaética iusmoralista, con una síntesis del constructivismo, que late en filósofos tan poco sospechosos, como HaBERMAS o RAWLS, entre otros de los que llevaron a cabo la llamada rehabilitación de la razón práctica, ALEXY alcanza su más relevante logro, en clave de sociología constitucional, como es que se piense que es progresista, liberador de los pueblos y protector de los derechos, un constitucionalismo iusmoralista, que quiere poner cortapisas a la soberanía popular, limitar los poderes del Poder Legislativo, más allá de lo que en los términos de las constituciones se establece, y hacer que la última palabra -dentro de los límites constitucionalmente marcados- sobre los derechos de los ciudadanos, no la tengan los Legisladores legítimos, mediante el instrumento constitucional de la Ley general, sino las judicaturas $\mathrm{y}$, en particular, los tribunales constitucionales más afines generalmente a los poderes decentes y más controlables, con las herramientas de la política tradicional y, por qué no más cercanos a las antiguas iglesias y los viejos cenáculos.

Lo que constituía para la teoría decimonónica el método silogístico, o el de la pura subsunción, lo es ahora el método de la ponderación ${ }^{19}$. Si aquéllos subsumían, los dworkinianos y alexyanos de ahora ponderan, unos y otros, convencidos de que el sistema jurídico es perfecto, en su fondo, de que la

19 Sobre el modo en que ALEXY contrapone subsunción y ponderación, véase Alexy, R. 2003. Críticamente, véase a GARZÓN CÁRDENAS. 2018, p. 133 y ss. 
discrecionalidad judicial no existe, o juega un papel marginal, o excepcional ${ }^{20}$ y de que con ayuda del método, en cuestión, puede el juez dar con la única solución correcta para cada caso, solución que no depende de su conciencia, sino del recto conocimiento que ese juez alcance, caso por caso, de lo que desde su fondo moral, el sistema jurídico prescribe. Los franceses de la escuela de la exégesis confiaban ciegamente en la lógica y la semántica y subsumían los hechos del caso, bajo las palabras de la Ley, que imaginaban siempre claras y definitivas; los alemanes de la jurisprudencia de conceptos subsumían los hechos, bajo los conceptos que los abarcaban, conceptos que, vistos con los anteojos del realismo conceptual, eran más que palabras, eran

20 El tema de la discrecionalidad judicial en ALEXY es discutido y merece un análisis más detenido aquí. AlEXY, desde luego, deja un cierto espacio para la discrecionalidad de los jueces y tribunales, cuando de la ponderación resulta un empate entre los principios enfrentados en la balanza. Pero, fuera de ahí, Alexy se centra en subrayar que sí hay importantes componentes de discrecionalidad del Legislador, en los espacios que el sistema cede a su libre decisión. La clave estaría, a mi entender, en que cuando el Legislador tiene discrecionalidad, el juez constitucional carece de competencia para someter a escrutinio y posible anulación sus decisiones, pero cuando el juez sí tiene tal competencia y pondera, la ponderación funciona como vía para la constatación de la solución judicial objetivamente correcta, -salvo que se constate empate en el peso, entre los principios enfrentados-, no como ejercicio de discrecionalidad valorativa de los jueces. Véase, por ejemplo, Alexy, R. 2009, p. 78 y ss.

Es muy equívoco AlEXY cuando dice, por ejemplo, que: La teoría de la ponderación, basada en la teoría de los principios, está intrínsecamente articulada con una teoría de la discrecionalidad. AleXY, R. 2015, p. 221. Como ahí mismo explica, se trata de que al Legislador se le reconocen sus espacios de decisión -jcómo podría ser de otro modo!-, y que la escala triádica, con que se pondera (grave, medio, leve), da pie, en ocasiones, a «puntos ciegos» y empates. Ibíd. pp. 221-223. 
entidades ideales (negocio jurídico, testamento, contrato, familia, patria potestad, prenda, propiedad, etc.), dotadas de un contenido metafísicamente necesario, inmutable y universal y sustraído a cualesquiera vaivenes sociales o políticos, conceptos que entre sí se encadenaban, según su grado de abstracción, formando algo parecido a aquel árbol genealógico del que habló el primer JHERING en cierta ocasión.

El constitucionalismo iusmoralista de Alexy y de Dworkin, sobre la base de la jurisprudencia de valores, cambia la materia prima del Derecho, el cual ya no se ve en enunciados, fruto de la razón jurídica imperecedera, ni en conceptos jurídicos universales y necesarios, sino en valores morales, constitucionalizados por sí hasta al margen de las palabras y los propósitos mismos del poder constituyente. Porque la moral es la Constitución y la Constitución verdadera no puede ser más que la versión jurídica de la verdadera moral, que es la moral verdadera. Precisamente, si ya no tiene sentido hablar de Derecho natural, como contraposición al Derecho positivo, es porque el Derecho natural se ha constitucionalizado y ahora éste no solo es ya Derecho positivo, sino Derecho positivo supremo, Derecho constitucional. Así lo dijo ya DürIG, en 1958, y así lo han repetido tantos luego como el propio ZAGREBELSKY, uno más de los que convierten lo dúctil del Derecho para poder someterlo al imperio de una moral rígida. Parece evidente que, si el Derecho natural se ha constitucionalizado, no ha sido a base de modificar sus esquemas, sino de mantenerlos indemnes, o adaptándolos a los tiempos; de la misma manera que el iusnaturalismo ha ido siempre acomodándose a la evolución social. No olvidemos, por ejemplo, que cualquier iusnaturalista de la actualidad ${ }^{21}$ afirmará,

21 Aunque quedan pocos, porque, para sus propósitos, ya no les hace 
sin ruborizarse, que el Derecho natural, siempre y en todo tiempo, ha estado a favor de la plena igualdad jurídica de hombres y mujeres, o del divorcio, o de la libertad sexual entre adultos con capacidad para consentir.

\section{Moral objetiva y decisión judicial correcta}

Si el Derecho no es solo ni principalmente lo que dicen las constituciones, las leyes, los reglamentos, o los repertorios jurisprudenciales, sino que es lo que manda la moral verdadera para cada caso y a base de concretar para ellos los contenidos prescriptivos, que se deducen de los valores morales en liza, la decisión correcta en Derecho tiene que ser la de un juez, que tenga recursos aprendidos o naturales para conocer lo que ese orden moral-jurídico de fondo determina y que posea un método capaz de traducir esas determinaciones de fondo a contenidos de la sentencia.

Dicho de otra manera, si para la escuela de la exégesis, la aplicación del Derecho no es más que un sencillo silogismo para el que vienen dados, con independencia de las valoraciones del juez, los contenidos de la premisa normativa y de la premisa fáctica, los fallos judiciales son esencialmente previsibles y los jueces son fungibles, en el sentido de que cualesquiera jueces, capaces de razonar correctamente y puestos ante el mismo caso, lo decidirán de manera idéntica. Si para la jurisprudencia de conceptos, la decisión judicial consiste en subsumir, o encajar los hechos del caso, perfectamente delimitables y averiguables, bajo los contenidos ontológicamente ciertos y patentes de las ideas, o conceptos jurídicos, nada más hace falta que los jueces tengan

falta ser iusnaturalistas, les basta hacerse principialistas y marcar los tiempos de la ponderación. 
la debida formación para conocer en detalle tales contenidos conceptuales y para entender el modo en que entre sí se ordenan y se encadenan; pero, sentado tal conocimiento, también son intercambiables los jueces, sin que varíen los contenidos de sus decisiones de los casos. Y si para el principialismo iusmoralista de ahora, en el subsuelo moral de los ordenamientos, los valores se acomodan, según un orden, que se manifiesta al pesar la manifestación de esos valores en los principios jurídicos, que concurren para cada caso, lo que importa es que el juez sepa de tales valores y principios y a partir de ese conocimiento y de un adecuado manejo de una balanza, cuyos resortes él no manipula, jueces diferentes pesarán o ponderarán igual, en el mismo caso, pues no tiene sentido pensar que, siendo objetiva la ponderación, varíe el resultado, dependiendo de quién pondere. Así que cuando en un tribunal de 5 magistrados, todos ponderan y deciden por mayoría y no por unanimidad, necesariamente alguno yerra, ya que por definición, no pueden haber ponderado todos igual de bien y llegado a resultados divergentes.

Un sistema jurídico, cuyos contenidos regulativos y prescriptivos para cada caso van más allá de los enunciados normativos positivos y sus indeterminaciones -vaguedad, ambigüedad, antinomias, lagunas-, no abre al juez un abanico de decisiones posibles -al tiempo que le cierra otras decisiones, por incompatibles con los enunciados normativos-, sino que le prescribe una decisión única para cada caso. Conforme a esas teorías de la única respuesta correcta, cuando el juez hace lo que debe, decide como debe, que es como el Derecho unívocamente le manda y de esa manera, tal juez ratifica ese sistema como plenamente objetivo.

En la economía, nos mueve la mano invisible del mercado y en el Derecho, nos determina la mano invisible de la moral. 
El Derecho opera, según su inmanente racionalidad jurídica, que es, en el fondo, una racionalidad moral. Somos tan libres como previsibles y porque somos, a la vez, libres y previsibles funcionan el mercado y el Derecho. Ahí, estaría esa especie de analogía estructural, entre la teoría económica clásica y la teoría jurídica clásica, sea en la versión del positivismo metafísico de la escuela de la exégesis y la jurisprudencia de conceptos, o sea en la adaptación casi posmoderna del iusmoralismo principialista. Y siempre con un objetivo inconfeso y aglutinador: que todo siga siendo como debe ser, a base de aparentar que las cosas ya son, en todo momento, como deben. Al menos sobre el papel, cada uno ya tiene lo suyo, sea según las reglas del mercado, sea de conformidad con los principios de la Constitución, y toda pretensión social o legislativa de alterar ese orden no solo es antieconómica o inconstitucional, sino que es, ante todo, inmoral. De eso es de lo que, en el fondo, se nos quiere convencer. Y por tal razón, la teoría que mejor se opone a la crítica al Derecho vigente, es la teoría iusmoralista al estilo del principialismo, pues si las constituciones ya son perfectas en sus contenidos axiológicos, ¿a ver cómo se pone usted a reprocharles injusticia a esas constituciones axiológicamente perfectísimas?

\section{Constructivismo ético y verdadera constitución}

No podemos captar bien el panorama, si no tomamos conciencia de lo que el constructivismo ético representa para el constitucionalismo iusmoralista de nuestros días. Las teorías de la única decisión correcta en Derecho presuponen algún tipo de sintonía, entre el sujeto que en Derecho decide y ese orden objetivo externo a él. Si el Derecho es un sistema normativo que, sea cual sea la materia prima de sus normas (enunciados legales producidos por el Legislador racional, conceptos, valores), 
contiene una única solución correcta predeterminada para cada litigio -o casi-, hará falta que los jueces posean algún atributo o don, o cuenten con algún método, que les lleve a descubrir esa solución, que dé pie a que esa solución se les manifieste cuando deban emitir sentencias. Sobre esto podría quizá decirse que del siglo XIX a la actualidad, hemos evolucionado de la fe a la razón teológica, o -permítaseme la broma- de una teología jurídica luterana a una más católica. En el siglo XIX, se venía a pensar que bastaba con la fe, o que la solución correcta del caso, se le hacía presente al juez algo así como por ósmosis. A un juez bien formado, usted lo coloca ante unos hechos y a él se le manifiesta la norma o el concepto, sin que deba hacer más que dejarse llevar por su impulso lógico; hechos y normas se acomodan solos, se aparean en la conciencia pasiva del juez y el fallo se genera como fruto de esa síntesis metafísica.

En cambio, el iusmoralismo actual, que abraza la idea de la única decisión correcta y que rechaza, o reduce a mínimos la discrecionalidad judicial, es más complejo a la hora de indicar cómo se le vuelve visible al juez esa decisión moral-jurídica, que el sistema le brinda para cada caso. Ya no se apela a la evidencia inmediata y el método se torna más intrincado. Particularmente para Alexy, es capital la aportación del constructivismo ético. No se sostiene que una elemental operación intelectual o un mero cálculo pueda llevar al juez a descubrir, en el sistema jurídicomoral, lo justo, sino que el juez ha de hacer abstracción de su subjetividad y, una vez que ha delimitado cuáles son los valores y principios concurrentes, debe preguntarse cómo decidirían ese caso cualesquiera sujetos racionales, que no estuvieran sometidos a condicionamientos y limitaciones de todo tipo; que buscarían el acuerdo de la comunidad ideal de habla o del auditorio universal; y, no dejarían de argumentar racionalmente 
con sus interlocutores, igual de racionales, hasta que se alcanzara el acuerdo sobre la solución mejor, que por ser la solución así racionalmente acordada, es la solución única objetivamente debida. Pues solución correcta para cada caso será aquélla sobre la que hipotéticamente podrían estar de acuerdo cualesquiera sujetos, que sobre las alternativas decisorias dialogasen en condiciones para argumentación ideales y con pleno respeto a las reglas de la argumentación racional.

Por tanto, el sujeto de carne y hueso que, como el juez, tiene que dirimir un conflicto, que es jurídico, sin dejar de ser, en su fondo, un conflicto moral ${ }^{22}$, ha de comenzar en sí mismo, planteándose las alternativas decisorias en el caso, y ha de salir luego de sí mismo para interrogarse acerca de cómo decidiría él, si en lugar de ser él, fueran muchos y en lugar de estar cognitivamente limitado como él está decidiera bajo condiciones de racionalidad perfecta. Y a ese juez, que por razón de sus limitaciones fácticas (falta de tiempo, insuficiencia de la información disponible, etc.) y cognitivas (no es un sabio absoluto, tiene lagunas en su formación, prejuicios, sesgos, ideología, etc.) no puede, por definición, descubrir cuál es la solución objetivamente correcta, se le pide que aplique la solución objetivamente correcta como si la hubiera podido descubrir; y, por tal motivo, se dice que no tienen discrecionalidad, sino que el decidir cada caso, está amarrado a la razón objetiva, independiente de él.

Uno de los más interesantes enigmas de la teoría jurídica alexyana está en cómo pueden conciliarse y combinarse el modelo de

22 Aunque quedan pocos porque, para sus propósitos, ya no les hace falta ser iusnaturalistas, les basta hacerse principialistas y marcar los tiempos de la ponderación. 
racionalidad argumentativa de la decisión judicial que Alexy nos presenta en su Teoría de la argumentación jurídica, con su fuerte inspiración constructivista, y el modelo de ponderación, que nos propone, a partir, principalmente, de su obra Teoría de los derechos fundamentales, ya patentemente formalista. Pero más allá de esa duda sobre la que no me toca extenderme aquí, en Alexy, antes en Dworkin, y en todo el constitucionalismo principialista actual está de un modo u otro presente esa idea de que la decisión correcta de cada caso en Derecho, no solo se encuentra predeterminada en el fondo axiológico del sistema jurídico y es cognoscible, a base de seguir cierto proceder metódico, que es más propio del razonamiento moral, que del razonamiento jurídico-formal o técnico-jurídico, sino que el juez hallará esa solución, tanto más cuanto más sea capaz de abstraerse de sí mismo y sus circunstancias y de razonar como un sujeto genérico, como un decidor perfectamente imparcial, como un ser dotado de razón, que consigue pensar, sin los condicionamientos de sus circunstancias y de su biografía. De ahí que desde esos patrones teóricos, se crea que, si todos los jueces fueran perfectamente racionales, todos decidirían de modo igual el mismo caso, porque, a la postre, la verdad no tiene más que un camino y ese camino es el mismo para AGAMENón o para su porquero.

Para el iusmoralismo de la única respuesta correcta, ante casos jurídicos iguales, tendrán igual motivo todos los sujetos para dar con la misma respuesta, que es la que en el fondo del sistema jurídico late y aguarda a ser aplicada; y si quienes deciden, a veces divergen, será debido a que existen defectos en el razonar, que concluyen el camino hacia la verdad objetiva y el orden debido. Porque, a la hora de la verdad, todo el que mentalmente visita el auditorio universal, vuelve de allá poseído por la solución 
justa del caso, que es la que aceptan imparcialmente todos esos individuos ideales, que en tal auditorio imaginario argumentan y acuerdan.

Insisto en que para el Derecho continental, está mal planteada esa antítesis y en que la contienda es entre racionalismo e irracionalismo jurídico. Así, por ejemplo, KELSEN, que en tantas cosas discrepaba del realismo jurídico empirista de Alf Ross, en su teoría de la decisión judicial se alinea con los irracionalistas, mientras que, sin embargo, autores de hoy, tales como Dworkin o AlEXY, tendrían que incluirse, sin duda, entre los racionalistas. Y, por otro lado, hay que recordar de nuevo que poco o nada tienen que ver las teorías formalistas de la decisión judicial con las teorías formalistas de la validez jurídica. La doctrina kelseniana es formalista, en cuanto a la validez del Derecho, pero indudablemente antiformalista en su concepción de la decisión judicial y de la praxis jurídica. Su teoría es pura, en cuanto teoría de la ciencia jurídica, pero radicalmente impura al explicar la decisión judicial y cuantas decisiones en el mundo del Derecho se expiden. Y bastantes de los iusmoralistas, quienes combaten a conciencia las teorías formalistas de la validez jurídica, podrían seguramente ser incluidos entre los que se acercan a una teoría formalista de la decisión judicial. Pues, insisto, si el contenido de la decisión correcta está de alguna manera predeterminado y es independiente por completo de la voluntad o discrecionalidad de quien decide, y si hay un método formal, como la ponderación, que vale para extraer con toda o mucha objetividad esa decisión correcta para cada caso, algo o mucho de formalista hay en tal teoría de la decisión judicial ${ }^{23}$. Lo contrario a decisión formalista

23 Oigamos a AlEXY sobre el peculiar formalismo de la ponderación: Comenzamos con la pregunta de si existe una estructura formal de la 
sería decisión discrecional y si no llamamos formalistas a los iusmoralistas, que en su teoría de la decisión judicial niegan la discrecionalidad, o la convierten en marginal, habría que buscar un término similar que los describiera.

El formalismo de la decisión judicial, por tanto, es una dirección de la teoría jurídica, que se opone a la afirmación de la discrecionalidad como propiedad insoslayable de la decisión de los jueces tal como afirman las principales corrientes iuspositivistas del siglo XX, empezando por KELSEN y HART y siguiendo con BobBio o FERRAJOLI, por no hablar del irracionalismo extremo del positivismo empirista, propio de los realistas jurídicos, antiformalistas radicales. El formalismo de la decisión judicial ${ }^{24}$ es característica definitoria de las teorías de la única respuesta correcta en Derecho. Si en el sistema jurídico está de algún modo predeterminada o prediseñada la solución, para cualquier

ponderación, que sea en algún sentido similar al esquema general de la subsunción. La respuesta que podemos dar ahora es positiva. A pesar de algunas diferencias importantes, la semejanza es sorprendente. En ambos casos se puede identificar un conjunto de premisas de las cuales es posible inferir el resultado. Ni la fórmula de la subsunción, ni la fórmula del peso contribuyen de manera directa a la justificación del contenido de esas premisas. En esa medida, ambas son completamente formales. Pero esto no tiene por qué aminorar el valor que hay en identificar la clase y la forma de las premisas que son necesarias para justificar el resultado. No obstante, la relación entre las premisas y el resultado es diferente. La fórmula de la subsunción representa un esquema que funciona de acuerdo con las reglas de la lógica; la fórmula del peso representa un esquema que funciona de acuerdo con las reglas de la aritmética. AleXY, R., en CóRDOBA, J. (trad.). 2003, p. 109. Ese peculiar formalismo de AleXY lo destaca, por ejemplo, Moreso: Mientras la subsunción es un esquema que trabaja con arreglo a las reglas de la lógica, la ponderación trabaja de acuerdo a las reglas de la aritmética. MoRESO, J. J. 2009, p. 230.

No de la teoría de la validez jurídica, repito. 
caso, se necesita algún razonamiento formal para que quien, en Derecho decide los casos, pueda hacer llegar a su conciencia, a su conocimiento, esa solución externa a él y que éste de ninguna manera determina o reconfigura. Podrá ser, por tanto, un cálculo lógico o aritmético, un pesaje, una intuición objetiva, o cualquier proceder, que afiance la correspondencia objetiva entre el fallo que el juez emite y lo que el sistema jurídico manda, que el juez falle al margen por completo de las preferencias de tal juez.

Así puestas las cosas, el mayor riesgo se encuentra en la desfiguración de la solución única, objetivamente correcta, que resulta de la interferencia de algún factor subjetivo del juez, sea su ideología, sus prejuicios, su interés, su moral personal, etc. El juez será tanto más fiel al resultado objetivo para cada caso que el sistema jurídico le señala, cuanto más salga de sí mismo, cuanto menos sea él mismo, como individuo situado y condicionado, y cuanto más se comporte como individuo genérico, como sujeto, sin atributos que lo individualicen, como observador radicalmente imparcial, cuanto menos personal y más mecánica sea su manera de ubicarse ante el caso; cuanto más, en suma, consiga el juez colocarse mentalmente en la rawlsiana posición originaria y bajo el velo de ignorancia, o cuanto más sea capaz de imaginarse como uno más de aquéllos que argumenten perfectamente soluciones racionales del perelmaniano auditorio universal o de la habermasiana situación ideal de diálogo.

Aquí es donde la teoría de la argumentación jurídica al estilo de AleXY se da la mano con el constructivismo ético. El sistema jurídico, concebido en clave iusmoralista como la de AlEXY, prescribe que la decisión judicial sea ante todo justa, y en caso de que haya una tensión fuerte, entre las demandas de la justicia y las del Derecho formal, vencerá la justicia y la decisión plenamente 
jurídica será, curiosamente, la decisión contra legem, porque como tantas veces resalta AlEXY, la decisión jurídica es un caso especial de la decisión práctica general y, por tanto, lo que a la postre busca siempre es la decisión moralmente correcta de cada caso, y gana la moral cuando es fuerte la tensión entre lo que la justicia prescribe y lo que la norma jurídico-positiva manda. Para eso sirven los principios, con su anclaje en valores morales, para justificar como plenamente jurídica la decisión contra legem, la decisión opuesta a la regla legal, presentada como decisión que no nace de una preferencia moral personal del juez o tribunal, sino como resultado objetivo de un pesaje, llevado a cabo conforme a los pasos del método ponderativo. Pesar o ponderar principios es una manera de sentar, caso a caso, cuál es la solución moralmente mejor para el caso jurídico; si la que prescribe la norma positiva, que venga al caso, o la que mande el principio de raigambre moral, que a esa norma positiva, en ese caso, se opone. Pues no debemos perder de vista que la ponderación, es una operación de cotejo moral $^{25}$, de opciones decisorias, es un esquema de razonamiento moral como corresponde a la radicalidad. Para ALEXY, el Derecho está al servicio de la moral, y a la rotundidad con la que pretende demostrar que jamás hay que hacer caso al Legislador, ni siquiera al más democrático, cuando su solución para un caso choque con las demandas claras de la moral verdadera.

\section{7. ¿Racionalidad argumentativa?}

¿Cómo puede el juez saber cuál es la solución moral y justa para el caso, a fin de ver si esa solución moralmente correcta, cuadra o no con la solución legalmente prevista? Aquí, repito, AlEXY ofrece dos opciones, que no me parecen muy fácilmente

25 Más ampliamente, véase GARCíA AmAdO, J. A. 2016a. 
conciliables. La primera y más obvia es la de la ponderación y, la otra, la de la racionalidad argumentativa. La ponderación consiste en pesar y aplicar la fórmula del peso, según esquema aritmético, que es distinto del esquema lógico de la mera subsunción, pero igualmente formal y formalista.

La racionalidad argumentativa consiste en exigir que los argumentos en pro de cada solución, se manejen no cotejándolos con las preferencias y creencias del juez o individuo, llamado a decidir el caso, sino del modo como los considerarían cualesquiera miembros de una comunidad de argumentadores perfectamente racionales e imparciales. Lo que ellos decidirían, en su caso, es lo que debe decidir el juez, que en realidad no es, ni puede ser uno de ellos, aunque lo desee y se le pida que lo intente. Ese es el paso, que va de Dworkin a Alexy. Mientras que el Hércules dworkiniano es un ideal puramente postulado, pero que no se desempeña en ningún sitio, el argumentador racional de AleXY es un humano genérico, quien vive en la teoría de una sociedad perfecta de argumentadores sin tacha. Hércules es un genio imaginado, pero el argumentador racional de ALEXY es cualquiera de nosotros, a quien postulamos, colocado en un contexto que asegure la imparcialidad de su razonamiento; cualquiera de nosotros, tal como somos, pero sin biografía, sin ideología, sin prejuicios, sin creencias definidas. Cualquiera de nosotros, como seres con biografía, ideología, prejuicios, creencias, debe decidir los casos, en tanto que el juez lo hace, como si estuviera allá y no aquí, como si fuera perfectamente racional e imparcial en lugar de ser como es. Hay que empezar por intentarlo, luego conviene creérselo y, a continuación, se decide, diciendo que ya está y que así fue ${ }^{26}$.

26 Estamos muy cerca de ese modelo de teórico o profesor de Derecho, 
Por su parte, las corrientes teóricas de estilo positivista, que proclaman la discrecionalidad judicial como elemento ineludible en la decisión ${ }^{27}$, ya sea en mayor o menor medida, según los casos, y que, por tanto, se oponen al formalismo de las teorías de la única decisión correcta en Derecho -o casi- ponen por delante lo que los otros niegan: la insoslayable influencia de los elementos subjetivos en la decisión judicial. Mientras lo que para los formalistas es un riesgo, que no logran ignorar, pero que tratan de desterrar, para los iuspositivistas o antiformalistas es una certeza, y se pueden buscar recursos para que esa inevitable discrecionalidad judicial, no degenere en incontrolable y fatídica arbitrariedad. Aquí, es donde podemos apreciar una escala de radicalidad, con su polo más optimista en quienes creen que caben instrumentos, que en alguna medida controlen el alcance y los efectos de la discrecionalidad judicial, y con su polo opuesto, en los más extremos irracionalistas, para quienes ningún modo existe de controlar la libérrima voluntad de los jueces y su poder para decidir cada caso como les dicte su preferencia o determine su moral. Para estos escépticos completos, la única vía que las sociedades tienen para evitar los desastres, derivados del supremo poder de los jueces para decidir como quieran; presentar sus decisiones, como resultado de lo más objetivo del

que ANDRÁs JÁKAB denomina modelo del teórico profeta, y que pretende siempre decir a los jueces cómo deben decidir. Ese modelo de teórico profeta considera que él sabe siempre cómo hay que decidir cada caso y que los jueces deben sentenciar, en correspondencia, con eso que él sabe, siguiéndolo a él. Su sabiduría proviene de un conocimiento profundo de los fundamentos de la vida social y de las supremas verdades morales, traducidas a principios jurídicos. Es un Hércules y, si lo seguimos a él, acabaremos siendo como él: pura luz, inmaculada sabiduría, portavoz de la verdad y la justicia para cada caso. Véase JÁKAB, A. 2011, p. 765 y ss.

Así, entre tantísimos, FerRAJOLI, L. 2011, p. 20. 
Derecho; y, sus más recónditos principios consiste en procurar que esos jueces, tengan una buena formación, sean socialmente responsables y cultiven una ética personal bien estricta, que los lleve a ser decentes y, en la medida de lo posible, considerados con los intereses del prójimo y no preocupados, únicamente, del cultivo esmerado de los suyos propios ${ }^{28}$.

Quienes no son tan irracionalistas o escépticos pueden llegar a algún acuerdo sobre la utilidad de las reglas argumentativas o del modelo de racionalidad argumentativa, como herramienta para un cierto control del uso que de sus márgenes de discrecionalidad el juez haga $^{29}$. Tres grupos podríamos mencionar aquí sintéticamente. Los formalistas de la única decisión correcta y que se inspiran en ALEXY y el constructivismo ético, piensan que la racionalidad argumentativa, en cuanto racionalidad imaginada en su ejercicio en una comunidad ideal de hablantes, sirve para mostrar el camino hacia la única respuesta jurídicamente válida, que es la única respuesta moralmente correcta, a la postre. Que no quede muy claro cuánto de esa decisión jurídica perfectamente objetiva y racional se consigue, mediante tal expediente constructivo-argumentativo y cuánto se alcanza a base de ponderar, siguiendo los tres pasos por ALEXY marcados -tests de idoneidad, necesidad y proporcionalidad, en sentido estricto-, es algo que, repito, no me toca analizar en este artículo; y tampoco puede aquí mi examen ir mucho más allá de señalar que en AlEXY, hay dos épocas y que la segunda, la de la ponderación, implica un énfasis

28 Sirva como ejemplo de este enfoque lo mucho que sobre la selección de los jueces, entre los juristas más expertos y mejor formados y los más decentes; sobre ellos escribieron los autores de la llamada escuela de Derecho libre, con ERNST FUCHS, a la cabeza, en Alemania, en los comienzos del siglo XX. Véase García Amado, J. A. 1997. 
formalista, que no aparecía en sus primeros tiempos, los de su libro Teoría de la argumentación jurídica.

Como segundo grupo, habría un positivismo jurídico no radical en su irracionalismo y no, necesariamente, vinculado al relativismo ético, o a posturas antiobjetivistas en metaética. Ese iuspositivismo moderado vería utilidad al modelo de racionalidad argumentativa no como vía, para el hallazgo de la única solución correcta, sino como instrumento para detectar decisiones judiciales, deficientemente racionales por falaces o insuficientemente argumentadas. Y en el tercer grupo estarían los que más próximos a un iuspositivismo empirista, de corte realista, que a uno normativista piensan que para nada sirve tampoco la teoría de la argumentación, con su énfasis en ciertos modelos de racionalidad argumentativa al tiempo de acotar o controlar la total libertad del juez cuando decide como mejor le parece y de justificar su decisión como mejor nos convenza.

Para los primeros, los iusmoralistas como AleXY, la racionalidad argumentativa es instrumento privilegiado de la razón práctica, que manda sobre el Derecho y la decisión judicial. Para los segundos, los iuspositivistas no completamente escépticos, la racionalidad argumentativa es una herramienta útil, práctica para detectar posibles decisiones arbitrarias, aunque no sirva para encontrar, o fundar la única decisión correcta en cada caso. Para los terceros, la racionalidad argumentativa es una revitalización de la simple retórica, con la que puede cualquiera que decida presentar seductoramente su decisión, si es hábil en el manejo de los recursos argumentativos.

A mi modo de ver, es indudable que la teoría de la argumentación, tal como la iniciaran precursores como VieHWeg, Perelman o 
RECASÉnS y así como se plasma en el primer AleXY, ha rendido frutos importantes a la teoría de la decisión judicial al margen de que se esté de acuerdo o no con la tesis del caso especial de Alexy y con su iusmoralismo. Quiero decir que hay un modelo básico de racionalidad argumentativa, que es asumible por cierto iuspositivismo, o por cualquier teoría no iusmoralista del Derecho. Son las bases de esa teoría, que compartieron autores, en algunos sentidos tan diferentes como Aarnio, PecZenick, Wróblewski, MacCormick, Alexy o Atienza, entre muchos otros. Esa que podríamos llamar teoría básica de la argumentación jurídica ha servido para rehabilitar la lógica formal como instrumento útil para el análisis de la racionalidad de las decisiones judiciales, dentro de su dimensión de justificación interna, según la archiconocida distinción introducida por WRÓBLEWSKI. También ha impulsado el estudio de las condiciones de uso racional de muy distintos argumentos, interpretativos y no interpretativos, frecuentes en la motivación de las sentencias. Y por mencionar una tercera utilidad difícilmente negable, la teoría básica de la argumentación ha incentivado el estudio en la teoría jurídica de las falacias y su uso y su papel en el razonamiento jurídico. 


\section{BIBLIOGRAFÍA}

AlEXY, R. "On Balancing and Subsuntion. A Structural Comparison", Ratio Iuris. N. ${ }^{\circ}$ 16, 2003. Hay dos traducciones al español: Ídem. "Sobre la ponderación y la subsunción. Una comparación estructural”, Pensamiento Jurídico. Córdoba Johanna (trad.). N. ${ }^{\circ} 16,2006$; ídem. "De la ponderación y la subsunción. Una comparación estructural", Montealegre Lynnettt, E., Bautista Pizarro, N., y Vergara Peña L. F. (comp.). La ponderación en el Derecho. Evolución de una teoría, aspectos críticos y ámbitos de aplicación en el Derecho alemán. Vergara Peña, Luis Felipe (trad.). Bogotá, Universidad Externado de Colombia, 2014.

"Sobre derechos constitucionales a protección". García Manrique, R. (ed.). Derechos sociales y ponderación. 2. ${ }^{\mathrm{a}}$ edición. Madrid, Fundación Coloquio Jurídico Europeo, 2009.

."Control judicial de constitucionalidad como representación argumentativa". Fabra Zamora, J. L., y García Jaramillo, L. (coords.). Filosofía del Derecho constitucional. Cuestiones fundamentales. Ciudad de México, Instituto de Investigaciones Jurídicas, Universidad Nacional Autónoma de México, 2015. 
ANDRÉS IBÁÑEZ, P. Los hechos en la sentencia penal. Ciudad de México, Fontamara, 2007.

BERNUZ BENÍTEZ, M. J. François Gény y el Derecho. La lucha contra el método exegético. Bogotá, Universidad Externado de Colombia, 2006.

BYDLINSKI, F. Juristische Methodenlehre und Rechtsbegriff. 2. edición. Wien, New York, Springer, 1991.

CALVO GARCÍA, M. "Metodología e interpretación: el postulado de la racionalidad del Legislador". Anuario de Filosofía del Derecho. N. . 3, 1986.

FERRAJOLI, L.Principia Iuris. Teoría del Derecho y de la democracia. Tomo 1: Teoría del Derecho. Andrés Ibáñez, P., Bayón, C., Gascón, M., Prieto Sanchís, L., y Ruiz Miguel, A. (trads.). Madrid, Trotta, Andrés Ibáñez, 2011.

GARCÍA AMADO, J. A. "Ernst Fuchs y la doctrina del Derecho libre". Anuario de Filosofía del Derecho. N. . 14, 1997.

. "Sobre formalismos y antiformalismos en la Teoría del Derecho. Eunomia”, Revista en Cultura de la Legalidad. N. ${ }^{\circ}$ 3, 2012.

.¿Qué es ponderar? Sobre implicaciones y riesgos de la ponderación", Revista Iberoamericana de Argumentación. N. ${ }^{\circ}$ 13, 2016 a.

. ¿Para qué sirve la teoría de la argumentación jurídica?”, Teoría \& Derecho. N. ${ }^{\circ}$ 20, 2016b. 
GARCíA SALGADO, M. J. La jurisprudencia de intereses de Philipp Heck. Granada, Comares, 2011.

GARZÓN CÁRDENAS, R. "La subsunción de Alexy y la pregunta por la racionalidad de la ponderación", Revista del Posgrado en Derecho de la UNAM. Nueva Época. N. ${ }^{\circ} 8,2018$.

GÜNTHER, F. "Jemand der sich schon vor fünfzig Jahren selbst überholt hatte. Die Nicht-Rezeption Hans Kelsens in der bundestdeutschen Staatsrechtslehre der 1950er und 1960er Jahren”. Jestaedt, M. (ed.). Hans Kelsen und die deutsche Staatsrechtslehre. Tübingen, Mohr Siebeck, 2013.

JÁKAB, A. "Seven Role Models of Legal Scholars", German Law Journal. N. . 12, 2011.

MORESO, J. J. "Alexy y la aritmética de la ponderación", García Manrique, R. (ed.). Derechos sociales y ponderación. 2. edición. Madrid, Fundación Coloquio Jurídico Europeo, 2009.

PaWlowsKi, H. M. Methodenlehre für Juristen. Heidelberg, Karlsruhe, C. F. Müller, 1981.

RÜCKEERT, J. y SEINECKE, R. "Zwölf Methodenregeln für den Ernstfall”. Rückert, J., y Seinecke, R. (eds.). Methodik des Zivilrechts von Savigny bis Teubner. 3. ${ }^{a}$ edición. Baden-Baden, Nomos, 2017.

SCHLINK, B. “¿Por qué Carl Schmitt? Precedente”, Revista Jurídica. N. . 47, 2005. 
SEINECKE, R. "Methode und Zivilrecht beim Begriffsjuristen Jhering (1818-1892)", Rückert, J., y Seinecke, R. (eds.). Methodik des Zivilrechts von Savigny bis Teubner. 3. edición. Baden-Baden, Nomos, 2017.

WESEL, U. Der Gang nach Karlsruhe. Das Bundesverfassungsgericht in der Geschichte der Bundesrepublik. Manchen, Karl Blessing, 2004.

ZACCHARIA, G. "Il Diritto come pratica interpretativa: Ronald Dworkin", Bongiovanni, G., Pino, G., e Roversi, C. (edits.). Che cosa è il Diritto. Ontologie e concezioni del giuridico. Torino, Giappichelli, 2016. 